\title{
Features of the Electrochemical Deposition of Films from a Triple System of CoNiFe
}

\author{
R. D. Tikhonov
}

\begin{abstract}
The nature of phenomena that occurs in the electrolyte during the electrochemical deposition of CoNiFe films and the mechanism leading to the difference in the relative content of elements in the electrolyte and film was clarified. This clarification was obtained with the help of a spectrophotometric study of chloride electrolytes and the electrochemical deposition of CoNiFe films at $70{ }^{\circ} \mathrm{C}$. An experimental study of the absorption spectra and the $\mathrm{pH}$ values of the $\mathrm{FeCl}_{2}, \mathrm{NiCl}_{2}$ and $\mathrm{CoCl}_{2}$ salt solutions at concentrations of 0.005 to $1 \mathrm{~mol} / \mathrm{l}$ showed the complex nature of the ionformation balance in single-component and mixed solutions and the dependence of ion formation on acidic and alkaline additives. The deposited CoNiFe film was made from a chloride electrolyte with a component content ratio of $1: 1: 1$ at both high $(0.5 \mathrm{~mol} / \mathrm{l})$ and low $(0.006 \mathrm{~mol} \mathrm{l})$ concentrations of each component. The content of each component in the film after the electrochemical deposition of the three component solution $\left(\mathrm{FeCl}_{2}, \mathrm{CoCl}_{2}\right.$, and $\mathrm{NiCl}_{2}$ at equal concentrations) did not correspond to the composition of the electrolyte. The mechanism for the abnormal deposition of $\mathrm{Co}, \mathrm{Fe}, \mathrm{Ni}$ occurred due to the incomplete ionization of atoms and the differences in the mobility of ions. The magnetic susceptibility of the films formed in the triple CoNiFe system was higher than that of a permalloy. Therefore, the triple system shows promise for use in magnetic field converters.
\end{abstract}

Index Terms - CoNiFe films, chloride electrolyte, ion balance, electrochemical deposition, spectrophotometric control.

\section{INTRODUCTION}

There are a large number of publications with research results that show the widespread use of a CoNiFe ternary alloy in microelectronic products and in magnetic memory with a high packing density. A CoNiFe electrochemical coating is used in many technological fields to reduce corrosion and wear in magnetic and electrical devices and to create electrocatalytic materials. Compared to "dry" processes, electrochemical deposition provides a more uniform coating with few defects and allows, if necessary, the ability to increase the thickness of the films without causing mechanical stress.

Magnetometric microsystems use thick (up to $100 \mu \mathrm{m}$ ) CoNiFe films obtained by electrolytic deposition from a sulfate electrolyte with the following concentrations in $\mathrm{mol} / \mathrm{l}: \mathrm{Co}-0.053 ; \mathrm{Ni}-0.18$ or $0.09,0.107,0.132$, and 0.18 ; and $\mathrm{Fe}-0.012-0.06$ or 0.36 with ammonium and boric acid complexing agents [1]. The use of saccharin and lauryl sulfate can ensure adhesion and decrease mechanical

Published on February 4, 2021

R. D. Tikhonov, SMC “Technological Centre”, Russia.

(email: r.tichonov@tcen.ru) stresses in the structure of films. The concentration of $\mathrm{Fe}$ affects the value of the saturation induction $\mathrm{BS}$, which can be in a range of 1.5 to $2.0 \mathrm{~T}$, while the value of the coercive force $\mathrm{Hc}$, as a rule, does not exceed $10 \mathrm{Oe}$ for the composition of alloys containing 40-50 at.\% Co, 15-30 at.\% $\mathrm{Ni}$ and $30-40$ at.\% Fe.

In [2], the authors presented the use of a sulfate electrolyte, without sulfur-containing organic additives, to manufacture thin Co65Ni12Fe23 magnetic films, with a relatively high magnetization saturation field $(2.1 \mathrm{~T})$, low coercive force $(1.2 \mathrm{Oe})$ and high resistance $(21 \mu \mathrm{Ohm} \cdot \mathrm{cm})$. However, these films had high mechanical stresses and an insufficiently high resistance to operate at frequencies above $100 \mathrm{MHz}$. Thus, the difference in magnetic properties is associated both with the composition of a film and with the difference in the structure of a film from that of the bulk material.

The deposition of FeCoNi films during pulsed feeding changes the ratio of impurities due to the competition between two phenomena of anomalous codeposition. With short pulses, iron enrichment and the limited diffusion of iron ions occur, while with long pulses, nickel enrichment occurs [3]. Soft magnetic properties for these films have been obtained and show a force $\mathrm{Hc}$ of $\sim 1$ Oe, a magnetic permeability $\mu$ of 1000 and a magnetization saturation BS of $2.15 \mathrm{~T}$.

Despite a large number of articles describing technology for the electrochemical deposition of a CoNiFe ternary system, there are still a number of unresolved problems, which are primarily associated with the effect of anomalous metal deposition.

Soft magnetic CoNiFe films were obtained by electrochemical deposition from a sulfate electrolyte with the addition of ammonium chloride and boric acid [4].

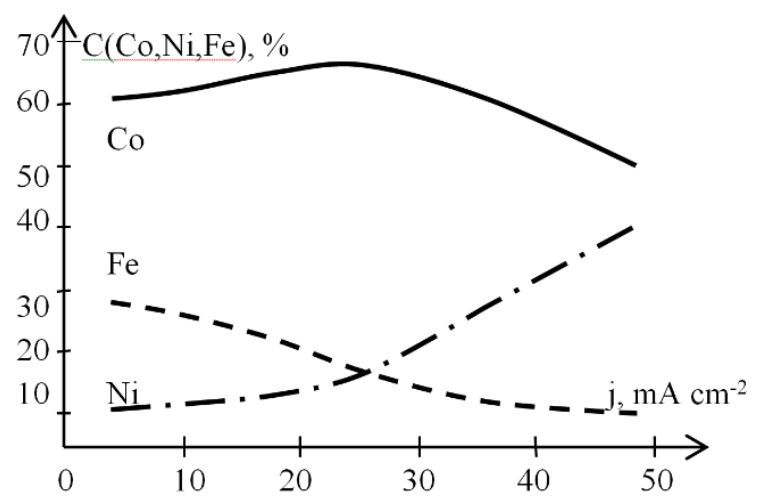

Fig. 1. Dependence of the CoNiFe content in films after electrochemical deposition with an electrolyte containing $\mathrm{Co}-19 \%, \mathrm{Ni}-46 \%$, and $\mathrm{Fe}-$ $35 \%$ at current densities of $4-49 \mathrm{~mA} / \mathrm{cm}^{2}$ [4] 
The composition of the precipitation was compared with the composition of the bath and the deposition conditions in the potential and current modes. Depending on the current density at the cathode, the composition of the films changed despite the composition of the electrolyte remaining the same, as shown in Fig. 1.

FeCoNi films were deposited by the electrochemical method from a sulfate chloride electrolyte [5] containing: $\mathrm{NiSO}_{4}-0.304 \mathrm{~mol} / \mathrm{l}, \mathrm{NiCl}_{2}-0.084 \mathrm{~mol} / \mathrm{l}, \mathrm{CoSO}_{4}-0.1 \mathrm{~mol} / \mathrm{l}$, $\mathrm{FeSO}_{4}-0.036 \mathrm{~mol} / \mathrm{l}, \mathrm{H}_{3} \mathrm{BO}_{3}-20 \mathrm{~g} / \mathrm{l}$, stabilizer-2 $\mathrm{g} / \mathrm{l}$, tartaric acid-4 g/l, bleach-4 g/l, and wetting agent and tartaric acid additives- $0.1 \mathrm{~g} / \mathrm{l}$. The optimum conditions for obtaining

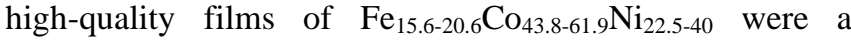
current density of $4 \mathrm{~A} / \mathrm{dm}^{2}$, a temperature of $40{ }^{\circ} \mathrm{C}$, a $\mathrm{pH}$ of 2.3-3.2, tartaric acid concentrations of 8-12 g/l, and $\mathrm{Co}^{2+} / \mathrm{Ni}^{2+}$ molar ratios of $0.26-0.4$. The composition of the film depended on the current density, electrolyte temperature, and $\mathrm{pH}$. The ratio of the content of elements in the electrolyte and the film was observed - CRL for Fe, $\mathrm{Co}=3$, and $\mathrm{Ni}=0.5$. The concentrations of cobalt and iron in the precipitate were larger than their concentrations in the electrolyte, while nickel showed the opposite result.

The above indicated that the dependence of the composition of a film of a ternary alloy does not allow one to obtain a desired film composition that corresponds to the composition of the electrolyte. As seen from the literature review, electrolyte compositions with a component concentration from 0.01 to $1 \mathrm{~mol} / \mathrm{l}$ have been used to obtain CoNiFe films.

In this work, to clarify the nature of the chemical phenomena occurring in the electrolyte when obtaining CoNiFe films, which is observed by the difference in the relative elemental content between the electrolyte and film, spectrophotometric studies of chloride electrolytes and the electrochemical deposition of CoNiFe films from a chloride electrolyte with an equal 1:1:1 molar concentration of Co:Ni:Fe were carried out at a temperature of $70{ }^{\circ} \mathrm{C}$; the experience of the congruent deposition of $\mathrm{NiFe}$ permalloy was also taken into account [6], [7]. The aim of this study is to determine the effect of ion charges in the electrolyte on the composition of the film.

\section{Study OF THE SPECTRA AND PH OF SAlt SOlutions}

The absorption spectra at room temperature of solutions at a component concentration of 0.005 to $1 \mathrm{~mol} / \mathrm{l}$ were studied [8] from 315 to $1050 \mathrm{~nm}$ in $1-\mathrm{cm}$ cells on a B-1100 spectrophotometer.

Fig. 2, 3, and 4 show optical spectra with absorption peaks at specific wavelengths for the following aqueous solutions: $\mathrm{FeCl}_{2}-345$ and $975 \mathrm{~nm}, \mathrm{NiCl}_{2}-395 \mathrm{~nm}$ and a double peak at 655 and $720 \mathrm{~nm}$, and $\mathrm{CoCl}_{2}-525 \mathrm{~nm}$.

The dependence of the logarithm of intensity of the absorption peaks (A) for single-component solutions of $\mathrm{FeCl}_{2} \cdot 4 \mathrm{H}_{2} \mathrm{O}-345 \mathrm{~nm}$ and $965 \mathrm{~nm}, \mathrm{NiCl}_{2} 6 \mathrm{H}_{2} \mathrm{O}-395 \mathrm{~nm}$ and $725 \mathrm{~nm}$, and $\mathrm{CoCl}_{2} 6 \mathrm{H}_{2} \mathrm{O}-525 \mathrm{~nm}$ from solution concentrations (C) in a range of $0.005-0.96 \mathrm{~mol} / \mathrm{l}$ are presented in Figure 5.

The optical absorption spectra of aqueous $\mathrm{FeCl}_{2}$ solutions, with absorption peaks at wavelengths of 345 and $975 \mathrm{~nm}$, are the most intense compared with the peaks of nickel and cobalt. This result indicates that iron had the lowest ionization energy. The absorption peak at a wavelength of $345 \mathrm{~nm}$ decreases linearly at a concentration of $0.05 \mathrm{~mol} / \mathrm{l}$. At a low concentration, the slope of $\mathrm{A}(\mathrm{C})$ dependence decreases. Furthermore, the absorption peak at a wavelength of $975 \mathrm{~nm}$ decreases nonlinearly when the electrolyte concentration is less than $0.2 \mathrm{~mol} / \mathrm{l}$.

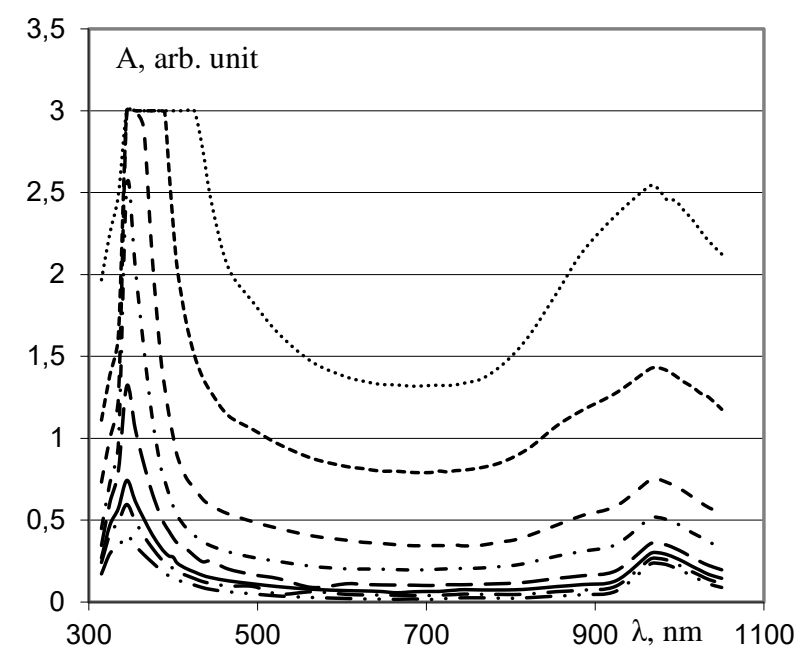

Fig. 2. Dependence of the optical absorption (A) at wavelengths of $315-$ $1050 \mathrm{~nm}$ for an aqueous solution of $\mathrm{FeCl}_{2} \cdot 4 \mathrm{H}_{2} \mathrm{O}$ at the following concentrations $(\mathrm{C}, \mathrm{mol} / \mathrm{l})$ :

$0.96,0.48,0.24,0.12,0.06,0.03,0.02,0.01$, and 0.005 .

This absorption peak is also present at a low intensity for solutions of $\mathrm{NiCl}_{2}$ and $\mathrm{CoCl}_{2}$ and changes when $\mathrm{HCl}$ is added to the electrolyte, which means that this peak is associated with the formation of chloride ions.

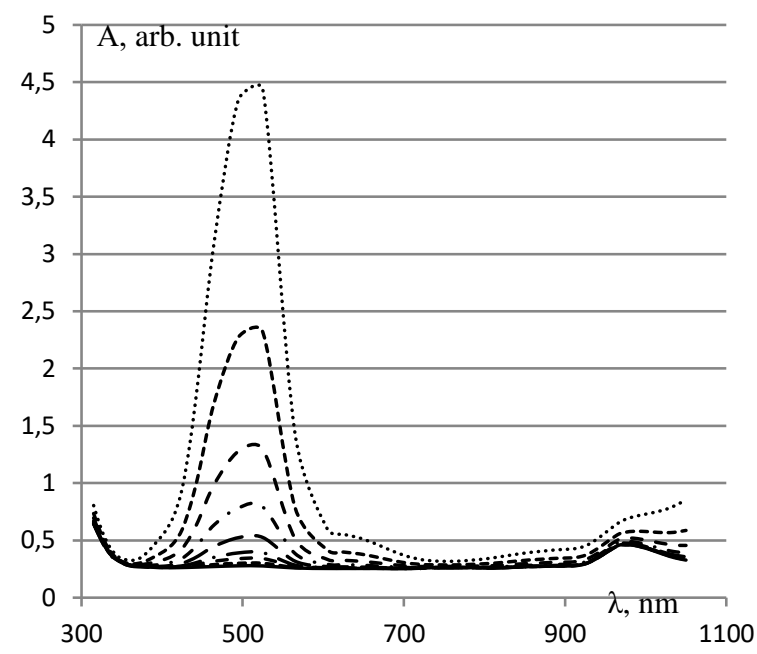

Fig. 3. Dependence of the optical absorption (A) at wavelengths of 315$1050 \mathrm{~nm}$ for aqueous solutions of $\mathrm{CoCl}_{2} \cdot 6 \mathrm{H}_{2} \mathrm{O}$ at the following concentrations $(\mathrm{C}, \mathrm{mol} / \mathrm{l})$ :

$0.96,0.48,0.24,0.12,0.06,0.03,0.02,0.01$, and 0.005 .

The dependence $\mathrm{A}(\mathrm{C})$ of the intensity of the cobalt peak at a wavelength of $525 \mathrm{~nm}$, as shown in Fig. 3, shows barely any change in its slope and is 5 times smaller than the peak of iron absorption at a wavelength of $345 \mathrm{~nm}$.

The $\mathrm{A}(\mathrm{C})$ dependence for nickel at a wavelength of 395 
$\mathrm{nm}$, as shown in Fig. 4, is very close to the $\mathrm{A}(\mathrm{C})$ dependence of a $\mathrm{CoCl}_{2}$ solution at a wavelength of $525 \mathrm{~nm}$ in terms of the intensities of absorption peaks. The $\mathrm{A}(\mathrm{C})$ dependences for nickel at a wavelength of $725 \mathrm{~nm}$ and iron at a wavelength of $965 \mathrm{~nm}$ are also very similar in that the slope changes at $0.2 \mathrm{~mol} / \mathrm{l}$; however, the absorption intensity of the nickel chloride solution is 2 times lower than the iron chloride solution.

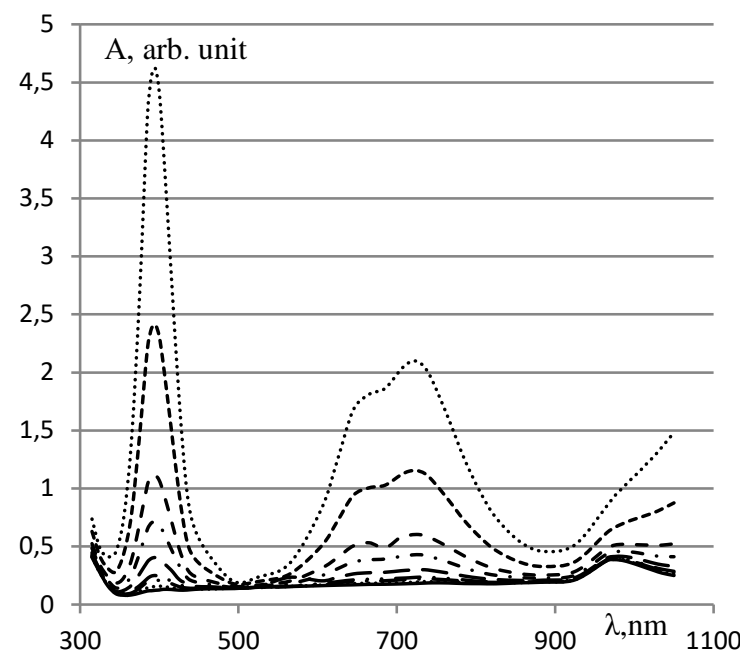

Fig. 4. Dependence of the optical absorption (A) at wavelengths of 315$1050 \mathrm{~nm}$ for aqueous solutions of $\mathrm{NiCl}_{2} \cdot 6 \mathrm{H}_{2} \mathrm{O}$ at the following concentrations $(\mathrm{C}, \mathrm{mol} / \mathrm{l})$ :

$0.96,0.48,0.24,0.12,0.06,0.03,0.02,0.01$, and 0.005 .

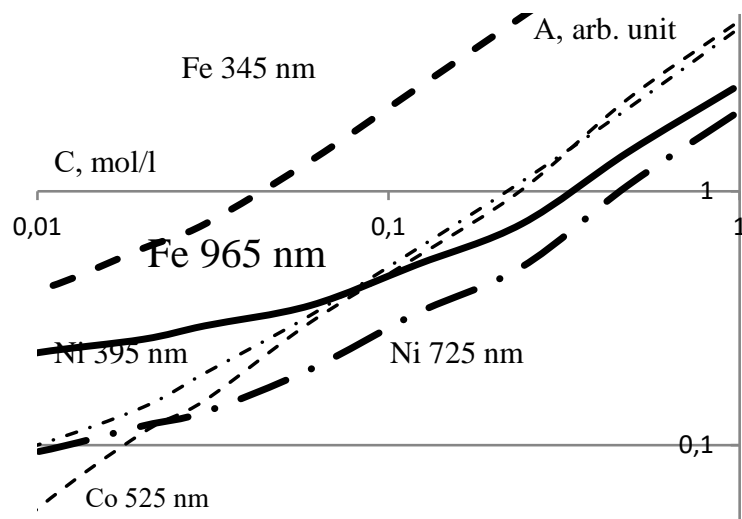

0,01

Fig. 5. Dependence of the logarithm of the intensities of absorption peaks (A) for the following single-component solutions: $\mathrm{FeCl}_{2} \cdot 4 \mathrm{H}_{2} \mathrm{O}-345$ $\mathrm{nm}$ and $965 \mathrm{~nm}, \mathrm{NiCl}_{2} \cdot 6 \mathrm{H}_{2} \mathrm{O}-395 \mathrm{~nm}$ and $725 \mathrm{~nm}$; and $\mathrm{CoCl}_{2} \cdot 6 \mathrm{H}_{2} \mathrm{O}-525$ $\mathrm{nm}$ from solution concentrations $(\mathrm{C})$ in a range of $0.005-0.96 \mathrm{~mol} / \mathrm{l}$.

The observed nonlinear dependence of the intensities of absorption peaks on the solution concentration for nickel and iron in Fig. 5 indicates the dependence of atomic ionization on the electrolyte concentration.

Fig. 6 shows the optical absorption spectra of aqueous solutions after mixing all three components. Lines 1-4 in Fig. 6 show that a mixed electrolyte, where the concentration of each component $\left(\mathrm{CoCl}_{2}, \mathrm{NiCl}_{2}, \mathrm{FeCl}_{2}\right)$ is $0.48 \mathrm{~mol} / \mathrm{l}$, has the same absorption peaks as the peaks observed for each component separately; additionally, the addition of boric acid and saccharin barely changes the spectrum. The spectrum of the solution after the addition of $4 \mathrm{mmol} / \mathrm{l} \mathrm{HCl}$ decreased the absorption intensity over the entire optical range because the electrolyte is purified from the colloidal hydroxide particles.

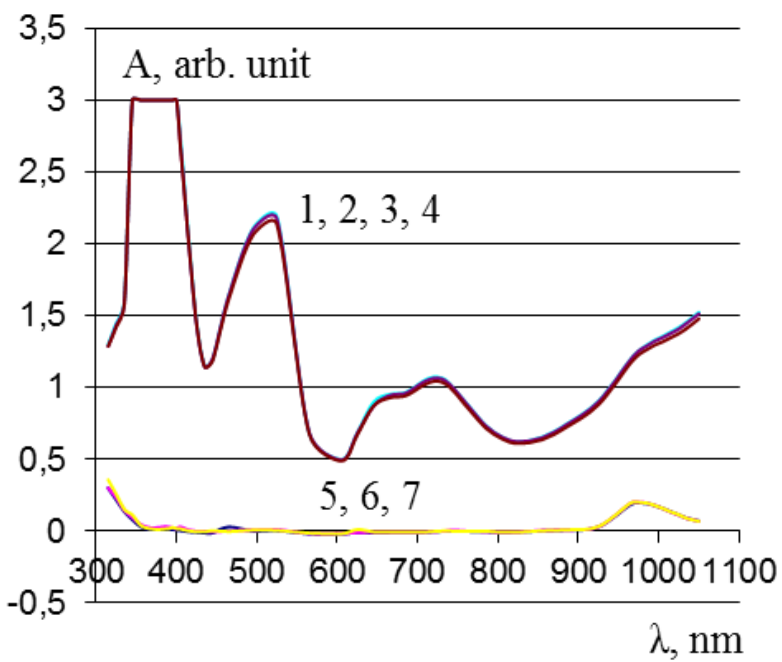

Fi. 6. Dependence of the optical absorption (A) at wavelengths of 315$1050 \mathrm{~nm}$ for the chloride electrolyte: 1 . At a concentration of $0.476 \mathrm{~mol} / \mathrm{l} \mathrm{o}$ each component, $\mathrm{CoCl}_{2}, \mathrm{NiCl}_{2}$, and $\mathrm{FeCl}_{2}$. 2. The electrolyte according to claim 1 , with the addition of $20 \mathrm{~g} / 1 \mathrm{H}_{3} \mathrm{BO}_{3}$. 3. The electrolyte according to claim 2 , with the addition of $1.5 \mathrm{~g} / 1$ saccharin. 4 . The electrolyte according to claim 3, with the addition of $3 \mathrm{ml} / 1 \mathrm{HCl}$. 5 . At a concentration of 0.0074 $\mathrm{mol} / \mathrm{l}$ of each component $\mathrm{CoCl}_{2}, \mathrm{NiCl}_{2}, \mathrm{FeCl}_{2}$. 6 . The electrolyte according to claim 5, with the addition of $20 \mathrm{~g} / \mathrm{H} \mathrm{H}_{3} \mathrm{BO}_{3}$. 7. The electrolyte according to claim 6 with the addition of $1.5 \mathrm{~g} / \mathrm{l}$ saccharin.

Lines 5-7 in Fig. 6 show that the electrolyte consisting of a mixture of $\mathrm{CoCl}_{2}, \mathrm{NiCl}_{2}$, and $\mathrm{FeCl}_{2}$ at a concentration of 0.0074 moll/l has the same absorption peaks as the peaks observed for each component separately, and the addition of boric acid and saccharin barely changes the spectrum. Moreover, the absorption intensity is much lower due to a 64-fold decrease in concentration.

\section{HydROGEN INDEX OF COCL $\mathrm{L}_{2}, \mathrm{NICL}_{2}, \mathrm{FeCL}_{2}$ SOLUTIONS}

In the $\mathrm{CoCl}_{2}, \mathrm{NiCl}_{2}$, and $\mathrm{FeCl}_{2}$ solutions, the $\mathrm{pH}$ was measured using a Testo 206 meter [8]. The dependence of $\mathrm{pH}$ on the concentration of one-component solutions over a concentration range of $0.01-1 \mathrm{~mol} / \mathrm{l}$ is shown in Fig. 7. At a concentration of $1 \mathrm{~mol} / \mathrm{l}$, dissolving $\mathrm{NiCl}_{2}$ exhibits a $\mathrm{pH}=5.8, \mathrm{CoCl}_{2}$ exhibits a $\mathrm{pH}=4.7$, and $\mathrm{FeCl}_{2}$ exhibits a $\mathrm{pH}=2.7$. The $\mathrm{pH}$ value characterizes the ion balance: the concentrations of hydrogen and hydroxyls, which in turn determines the acidity or alkalinity of water. Consequently, the hydrolysis of ferric chloride decreases the concentration of hydrogen during the dissociation of water the most and increases the hydroxyl amount.

Changes in $\mathrm{pH}$ during the dilution of a solution are not monotonic, but there are local peaks that appear along with changes in slope, thereby showing some dependence. This result means that a decrease in the concentration of impurities is accompanied by a change in the degree of ionization and the charge values of ions. The presence of local peaks is dependent on different salt concentrations: $\mathrm{NiCl}_{2}-0.5 \mathrm{~mol} / \mathrm{l}, \mathrm{CoCl}_{2}-0.03 \mathrm{~mol} / \mathrm{l}$, and $\mathrm{FeCl}_{2}-$ 
$0.02 \mathrm{~mol} / \mathrm{l}$. To obtain the same level of salt ionization, it is necessary to have solutions of each of the salts on the order of $1 \mathrm{~mol} / \mathrm{l}$ or $0.01 \mathrm{~mol} / \mathrm{l}$.

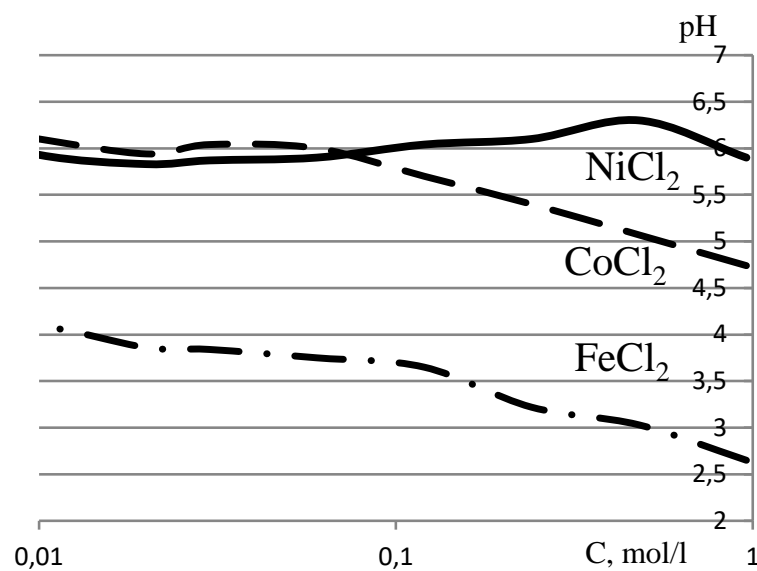

Fig. 7. Dependence of the $\mathrm{pH}$ of $\mathrm{CoCl}_{2}, \mathrm{NiCl}_{2}$, and $\mathrm{FeCl}_{2}$ solutions on the concentration $(\mathrm{C})$.

Prior to the peaks, the dependence of $\mathrm{pH}$ on salt concentration are linear. After the peaks, there is practically no dependence of $\mathrm{pH}$ on the concentration of $\mathrm{NiCl}_{2}$ and $\mathrm{CoCl}_{2}$ salts, but for $\mathrm{FeCl}_{2}$ salt, there is a change; however, this change is at a slower rate than that in the linear section.

Table 1 presents the results of calculating the $\mathrm{pH}$ of the three-component electrolyte in which the concentration of each component was from 0.01 to $1 \mathrm{~mol} / \mathrm{l}$. The calculation was carried out by summing the concentrations of hydrogen ions in the $\mathrm{CoCl}_{2}, \mathrm{NiCl}_{2}, \mathrm{FeCl}_{2}$ solutions, in accordance with the measured $\mathrm{pH}$ values shown in Fig. 7 for the singlecomponent solutions.

TABLE 1: ESTIMATED PH VALUES OF THE TERNARY ELECTROLYTE OBTAINED BY MEASURING THE PH VALUES OF THE ONE-COMPONENT

\begin{tabular}{ccccc}
\multicolumn{5}{c}{ SOLUTIONS } \\
\hline & $\mathrm{C}, \mathrm{M} /$ & $\mathrm{pH}$ & $\begin{array}{c}\mathrm{C}(\mathrm{H}+), \\
\mathrm{g} \mathrm{ion} / \mathrm{l}\end{array}$ & $\begin{array}{c}\mathrm{C}(\mathrm{OH}-), \mathrm{g} \\
\text { ion/l }\end{array}$ \\
\hline $\mathrm{NiCl}_{2}$ & 1 & 5,8 & $10^{-5,8}$ & $10^{-8,2}$ \\
$\mathrm{CoCl}_{2}$ & 1 & 4,75 & $10^{-4,75}$ & $10^{-9,25}$ \\
$\mathrm{FeCl}_{2}$ & 1 & 2,7 & $10^{-2,7}$ & $10^{-11,3}$ \\
$\mathrm{NiCl}_{2}+$ & & & & \\
$\mathrm{CoCl}_{2}+$ & $1+1+1$ & 2,6958 & $10^{-2,6958}$ & $10^{-11,3042}$ \\
$\mathrm{FeCl}_{2}$ & & & & \\
$\mathrm{NiCl}_{2}$ & 0,01 & 5,9 & $10^{-5,9}$ & $10^{-8,1}$ \\
$\mathrm{CoCl}_{2}$ & 0,01 & 6,1 & $10^{-6,1}$ & $10^{-7,9}$ \\
$\mathrm{FeCl}_{2}$ & 0,01 & 4,1 & $10^{-4,1}$ & $10^{-9,9}$ \\
$\mathrm{NiCl}_{2}+$ & $0,01+$ & 4,08892 & $10^{-4,08892}$ & \\
$\mathrm{CoCl}_{2}+$ & $0,01+$ & & & $10^{-10,91108}$ \\
$\mathrm{FeCl}_{2}$ & 0,01 & & & \\
\hline
\end{tabular}

The hydrolysis of iron chloride increases the concentration of hydrogen and decreases the hydroxyl amount, i.e., this hydrolysis increases the acidity of the solution more than the hydrolysis of the other two salts. In fact, the hydrolysis of iron chloride determines the $\mathrm{pH}$ of the mixed electrolyte over the entire range of component concentrations from 0.01 to $1 \mathrm{moll} / \mathrm{l}$ of a ternary electrolyte with equal concentrations of all three salts of $\mathrm{CoCl}_{2}, \mathrm{NiCl}_{2}$, and $\mathrm{FeCl}_{2}$.

Fig. 8 shows the calculated values of the ternary electrolyte $\mathrm{pH}$ obtained from the $\mathrm{pH}$ measurement data of the one-component solutions, as shown by the dashed line (1). The experimental $\mathrm{pH}$ values of the ternary electrolyte are shown by the dashed line and the solid trend line (2).

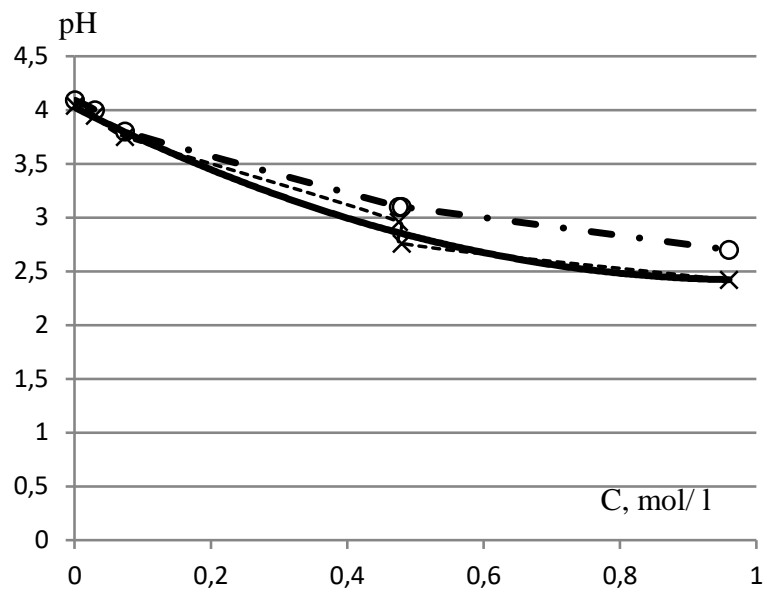

Fig. 8. Dependence of the $\mathrm{pH}$ of electrolyte for the electrochemical deposition of $\mathrm{CoNiFe}$ on the concentration (C) of each component.

The $\mathrm{pH}$ values of the CoNiFe ternary electrolyte obtained experimentally and in the calculation, based on the $\mathrm{pH}$ values of the one-component solutions of $\mathrm{FeCl}_{2} \cdot 4 \mathrm{H}_{2} \mathrm{O}$, $\mathrm{NiCl}_{2} \cdot 6 \mathrm{H}_{2} \mathrm{O}$, and $\mathrm{CoCl}_{2} \cdot 6 \mathrm{H}_{2} \mathrm{O}$ salts, almost completely coincide at low solution concentrations, while at a concentration of $1 \mathrm{~mol} / \mathrm{l}$, the calculated values are $10 \%$ higher than the experimental values. We can assume that each of the salts provides its own independent contribution to the hydrogen index, i.e., the change in the concentration of hydrogen ions regardless of the presence of other salts.

An experimental study of the absorption spectra and the $\mathrm{pH}$ of the $\mathrm{FeCl}_{2}, \mathrm{NiCl}_{2}$, and $\mathrm{CoCl}_{2}$ salt solutions at a concentration of up to $1 \mathrm{~mol} / \mathrm{l}$ shows the complex nature of the formation of ionic balance in the single and mixed solutions and the dependence of this balance on the acidic and alkaline additives.

\section{ElECTROCHEMICAL DEPOSITION OF THE CONIFE FILMS}

For the deposition of CoNiFe films, a chloride electrolyte with a component content ratio of 1:1:1 was used. To improve the deposition process, the following was added to the electrolyte: boric acid $\mathrm{H}_{3} \mathrm{BO}_{3}$ and sodium saccharinity hydrate $\mathrm{C}_{7} \mathrm{H}_{4} \mathrm{NaNO}_{3} \mathrm{~S} \cdot 2 \mathrm{H}_{2} \mathrm{O}$. A film of this electrolyte was deposited in an electrochemical installation with a 2-liter galvanic bath and a graphite anode. The nickel ring electrode of the cathode was in contact with a metallized silicon wafer and was placed vertically. Rectangular regions of a permalloy film $\left(0.5 \times 1.0 \mathrm{~mm}^{2}\right)$ were obtained through a photoresist mask on a silicon wafer surface (diameter of 100 $\mathrm{mm}$ ) metallized with $\mathrm{NiCr}$ and $\mathrm{Ni}$ layers along with containing a $\mathrm{SiO}_{2}$ sublayer.

The following characteristics of the obtained films were measured: the film thickness and content of the $\mathrm{Fe}, \mathrm{Co}, \mathrm{Ni}$ components; and the magnetic properties of the films, namely, the saturation of magnetization and coercive force. The thicknesses of the deposited films were measured using an MSA-500 microsystem analyzer. The study of the magnetic characteristics — coercive force and magnetization - was carried out with plates and an instrument for monitoring magnetic parameters. The 
compositions of the films were studied using a PhilipsXL 40 energy dispersive X-ray microanalyzer.

For the deposition of $\mathrm{CoNiFe}$ films with a weak electrolyte, the composition of the film without additives is closest to the relative electrolyte composition.

At a high electrolyte concentration of the three component solutions $\left(\mathrm{CoCl}_{2}, \mathrm{NiCl}_{2}\right.$, and $\mathrm{FeCl}_{2}$ at a concentration of $0.48 \mathrm{~mol} / \mathrm{l}$ for each component), electrochemical deposition was carried out at a cathode current density of $8.2 \mathrm{~mA} / \mathrm{cm}^{2}$, a temperature of $70{ }^{\circ} \mathrm{C}$ and with additives of $20 \mathrm{~g} / \mathrm{l}$ boric acid and $3 \mathrm{~g} / \mathrm{l}$ saccharin.

The compositions of films obtained from the three component solutions $\left(\mathrm{FeCl}_{2}, \mathrm{CoCl}_{2}, \mathrm{NiCl}_{2}\right)$ with additives is presented as a histogram in Fig. 9. According to the data in the figure, the content of the components is very different from the composition of the electrolyte without additives. The boric acid, saccharin, and hydrochloric acid additives decrease the content of iron and cobalt and increase the content of nickel. A three-fold increase in the deposition time to 90 minutes with sample 20 increased the iron and cobalt contents and decreased the nickel content; therefore, the composition of the film depends on the deposition time.

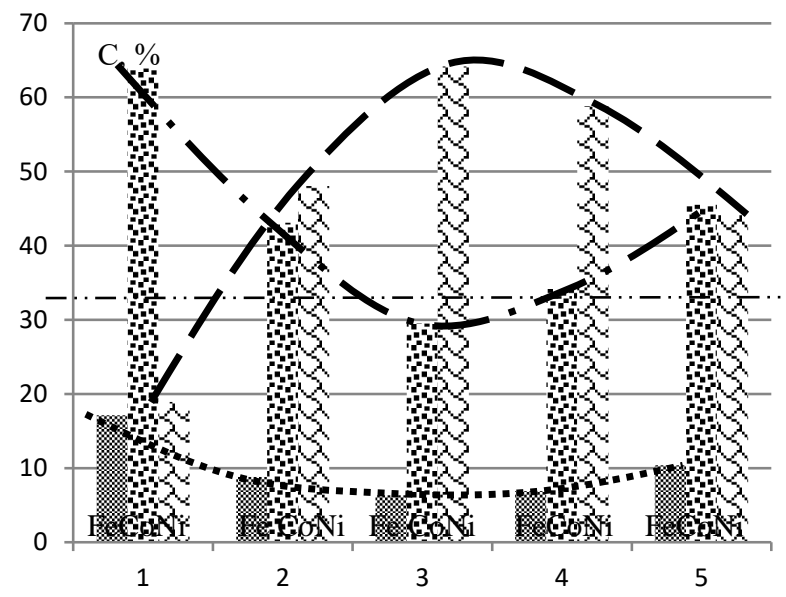

Fig. 9. Histogram of the compositions of films obtained from the three component solutions $\left(\mathrm{FeCl}_{2}, \mathrm{CoCl}_{2}, \mathrm{NiCl}_{2}\right)$ at a concentration of $0.48 \mathrm{~mol} / \mathrm{l}$ for each component (1) and with the following additives: boric acid (2), saccharin (3), and hydrochloric acid (4). Additionally, the component concentrations of the film when the deposition time was increased by 3 times (5).

A feature of the $\mathrm{FeCl}_{2}$ salt is the oxidation of ferrous iron to a trivalent state. The chemical powder initially has a light yellow-green color. With prolonged storage, rusty inclusions of ferric oxides appear. In a solution of such a chemical, the absorption of light increases with the addition of boric acid over the entire measured range of light lengths on hydroxide and boric acid complexes. When filtering a solution with oxidized iron chloride, rust particles remain on the filter.

The density of electric current flowing through the surface of the substrate on the cathode and its effect on the composition of the films was checked by electrochemical deposition from an electrolyte with a concentration of $0.5 \mathrm{~mol} / 1$ for each component along with the addition of boric acid, saccharin and hydrochloric acid. This test was conducted at cathode current densities of $5-20 \mathrm{~mA} / \mathrm{cm}^{2}$ and a temperature of $70{ }^{\circ} \mathrm{C}$; additionally, the solution of iron chloride was filtered. The dependence of the composition on current density is shown in Fig. 10.

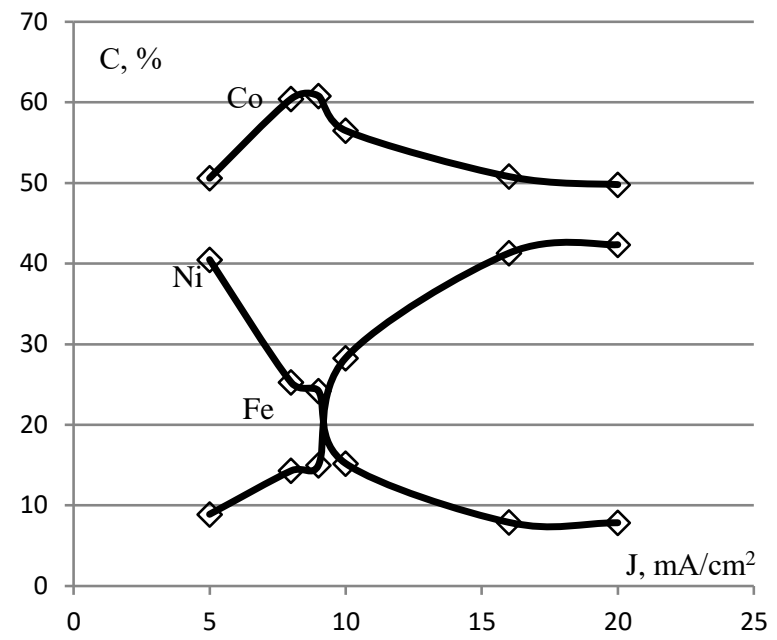

Fig. 10. Dependence of the compositions of films obtained from the three component solutions $\left(\mathrm{CoCl}_{2}, \mathrm{NiCl}_{2}, \mathrm{FeCl}_{2}\right)$ at a concentration of $0.5 \mathrm{~mol} / \mathrm{l}$ for each component with boric acid, saccharin, and hydrochloric acid additives on electric current densities of 5-20 mA/ $\mathrm{cm}^{2}$; additionally, the solution of iron was filtered.

The relative contents of the $\mathrm{Co}, \mathrm{Ni}$, and $\mathrm{Fe}$ components in the film differ from the electrolyte composition (with a content of $33.3 \%$ for each component) and varies greatly depending on the current density from 5 to $20 \mathrm{~mA} / \mathrm{cm}^{2}$. With an increase in the current density from 5 to $15 \mathrm{~mA} / \mathrm{cm}^{2}$ in the $\mathrm{CoNiFe}$ film, the iron content increases from 8.9 to $41.3 \%$, while at a current density of $20 \mathrm{~mA} / \mathrm{cm}^{2}$, it remains at the same level of $42.35 \%$. With an increase in the current density from 5 to $15 \mathrm{~mA} / \mathrm{cm}^{2}$ in the CoNiFe film, the nickel content decreases from 38.5 to $7.9 \%$, while at a current density of $20 \mathrm{~mA} / \mathrm{cm}^{2}$, it remains at the same level of $7.85 \%$. The actual change in the content of iron and nickel at a current density of $10 \mathrm{~mA} / \mathrm{cm}^{2}$ changes the cobalt content in the overall balance to $60.8 \%$. At a current density of 5 , 15 , and $20 \mathrm{~mA} / \mathrm{cm}^{2}$, the cobalt content has close values of $50.6,50.8$, and $49.8 \%$, respectively.

The general character of the $\mathrm{C}(\mathrm{J})$ dependence, along with the observations of a high cobalt concentration, a decrease in nickel concentration, and an increase in iron concentration with increasing current density coincides with the data of [5], despite the difference in the composition of the two electrolytes and the difference in the current density range. The difference in anions has an insignificant effect; therefore, the change in the composition of the films from the current density is determined by the $\mathrm{Co}, \mathrm{Ni}$, and $\mathrm{Fe}$ cations.

The relative content of the $\mathrm{Fe}, \mathrm{Co}, \mathrm{Ni}$ components in the film differs from the composition of the electrolyte and varies greatly depending on the current density. It is difficult to select a mode that ensures the reproduction of the electrolyte composition in the deposited film.

The plot of the film composition in a current range of 15$20 \mathrm{~mA} / \mathrm{cm}^{2}$ has an almost constant value, which makes it possible to set the concentrations of the components in the electrolyte to provide the desired composition in the film.

In this regard, the weighting coefficients of the components in the film are determined: $\mathrm{k}_{\mathrm{Co}}=\mathrm{Co}_{\mathrm{S}}(2): \mathrm{Co}_{\mathrm{S}}$ (1); $\mathrm{k}_{\mathrm{Ni}}=\mathrm{Ni}_{\mathrm{S}}(2): \mathrm{Ni}_{\mathrm{S}}(1) ; \mathrm{k}_{\mathrm{Fe}}=\mathrm{Fe}_{\mathrm{S}}(2): \mathrm{Fe}_{\mathrm{S}}$ (1), which provides the electrolyte composition. 


$$
\begin{aligned}
& \mathrm{Co}_{\mathrm{E}}(2)=\mathrm{Co}_{\mathrm{E}}(1) \times \mathrm{k}_{\mathrm{Co}} \\
& \mathrm{Ni}_{\mathrm{E}}(2)=\mathrm{Ni}_{\mathrm{E}}(1) \times \mathrm{k}_{\mathrm{Ni}} \\
& \mathrm{Fe}_{\mathrm{E}}(2)=\mathrm{Fe}_{\mathrm{E}}(1) \times \mathrm{k}_{\mathrm{Fe}}
\end{aligned}
$$

\section{Magnetic Properties of the CoNiFe FiLMS}

The distribution of values of coercive force and specific values of saturation of magnetic induction depending on the composition of the ternary $\mathrm{CoNiFe}$ alloy in films obtained by electrochemical deposition from a chloride electrolyte is presented in Fig. 11.

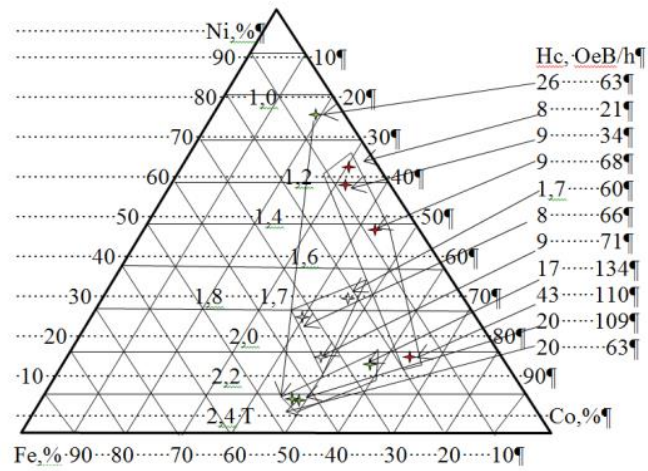

Fig. 11. Distribution of values of coercive force and specific values of saturation of magnetic induction depending on the composition of the ternary $\mathrm{CoNiFe}$ alloy in films obtained by electrochemical deposition from a chloride electrolyte.

For comparison [9], [10], Fig. 12 and 13 show the thickness-normalized magnetization and the derivative of the normalized magnetization of the $\mathrm{Co}_{43.1} \mathrm{Ni}{ }_{35.3} \mathrm{Fe}_{21.6}$ (1) and $\mathrm{Ni}_{81.6} \mathrm{Fe}_{18.4}$ (2) films depending on the applied magnetic field. The steepness of the magnetization line of the ternary system is 1.7 times higher, which allows us to consider the promising use of a ternary system in magnetic field converters. The scatter of the saturation values of magnetization flux and coercive force is large in accordance with the scatter of the compositions of the films.

Fig. 14 shows the configuration of a $12-\mu \mathrm{m}$ thick $\mathrm{CoNiFe}$ film obtained from three component solution $\left(\mathrm{FeCl}_{2}, \mathrm{CoCl}_{2}\right.$, $\mathrm{NiCl}_{2}$ ) at a concentration of $0.48 \mathrm{~mol} / \mathrm{l}$ for each component along with the following additives: boric acid, saccharin and hydrochloric acid.

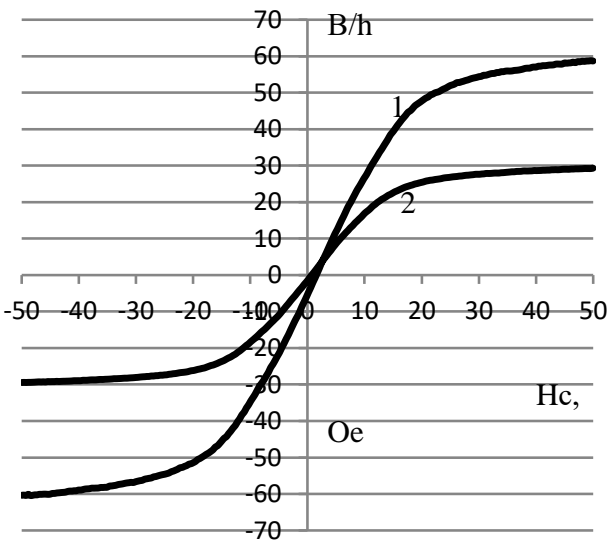

Fig. 12. Normalized thickness dependence of the magnetization of the
$\mathrm{Co}_{43.1} \mathrm{Ni}_{35.3} \mathrm{Fe}_{21.6}(1)$ and $\mathrm{Ni}_{81.6} \mathrm{Fe}_{18.4}$ (2) films.

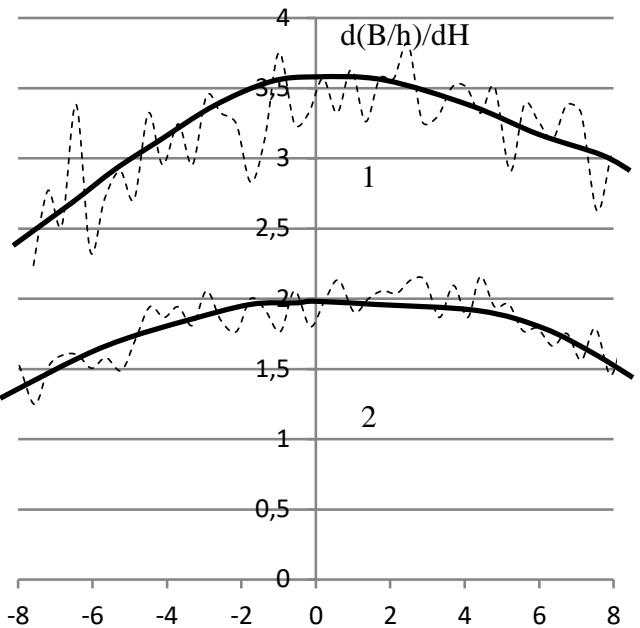

Fig. 13. First derivative of the normalized dependence of the magnetization of the $\mathrm{CoNiFe}(1)$ and $\mathrm{NiFe}(2)$ films.

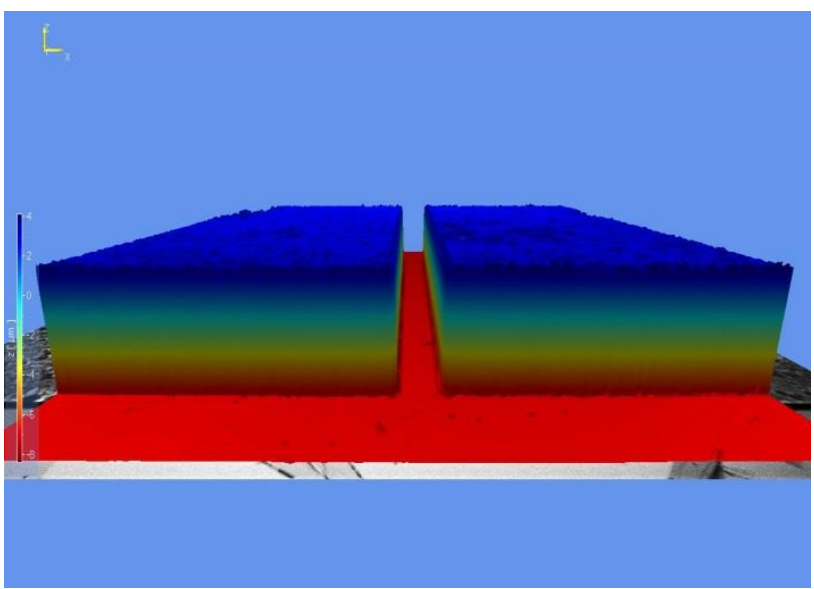

Fig. 14. Configuration of $12-\mu \mathrm{m}$ thick CoNiFe films obtained by loca electrochemical deposition from a concentrated electrolyte.

\section{DISCUSSION OF THE RESULTS}

An experimental study of the absorption spectra and $\mathrm{pH}$ of the solutions of $\mathrm{FeCl}_{2}, \mathrm{NiCl}_{2}$, and $\mathrm{CoCl}_{2}$ salts at a concentration of up to $1 \mathrm{~mol} / \mathrm{l}$ shows the complex nature of the formation of ionic balance in the single and mixed solutions and their dependence on acidic and alkaline additives. The content of components in the film during electrochemical deposition from a three-component solution $\left(\mathrm{FeCl}_{2}, \mathrm{CoCl}_{2}, \mathrm{NiCl}_{2}\right)$ with an equal concentration of each component does not correspond to the composition of the electrolyte. The closest result to the relative composition of the electrolyte is the composition of the film during the deposition with an electrolyte at a low concentration of each component.

In works on the electrochemical deposition of iron, nickel and cobalt, these metals in the electrolyte are considered divalent ions, in accordance with the valency of the metalforming salt. However, the ion charge in the electrolyte has not been studied, despite atoms being ionized during stepwise electrolytic dissociation and hydrolysis in water in accordance with the ionization energy of the electronic levels of salts. The incomplete dissociation of salts in the electrolyte has a significant effect on the rate of 
electrochemical deposition due to the dependence of the current efficiency on the charge of ions, which creates a current at the cathode. The following is an analysis of the factors determining the deposition of metal ions.

\section{A. Ionic Water Balance}

Water dissociates very weakly into $\mathrm{H}_{2} \mathrm{O} \leftrightarrow \mathrm{H}^{+}+\mathrm{OH}^{-}$ ions. The equilibrium between water molecules and ions is strongly biased toward the formation of molecules [11]. At a constant temperature, the product of the concentrations of hydrogen and hydroxyl ions is a constant value for water and weak aqueous solutions. At a temperature of $25^{\circ} \mathrm{C}$, the ionic product of water $\left[\mathrm{H}^{+}\right] \cdot\left[\mathrm{OH}^{-}\right]=10^{-14} \mathrm{~g}$-ion/l, where $\mathrm{pH}$ $=-\log \left[\mathrm{H}^{+}\right]$and $\mathrm{H}^{+}$is the concentration of hydrogen ions in gram-ion/l. Additionally, salt additions alter the $\mathrm{pH}$. The following are the $\mathrm{pH}$ ranges for each type of medium: an acidic medium $10^{-1}<\left[\mathrm{H}^{+}\right]>1.10^{-7}-\mathrm{pH}<7$, a neutral medium $\left[\mathrm{H}^{+}\right]=\left[\mathrm{OH}^{-}\right]=1.10^{-7}-\mathrm{pH}=7$, and an alkaline medium $1.10^{-7}<\left[\mathrm{H}^{+}\right]<1.10^{-14}-\mathrm{pH}>7$. The ion concentration is calculated by the hydrogen index from the ionic product of water. The electrolyte with a $\mathrm{pH}=5$ has a hydrogen concentration of $10^{-5} \mathrm{~g}$-ion/l and a concentration of hydroxide ions of $10^{-9} \mathrm{~g}$-ion $/ 1$.

\section{B. Dissociation of Salts in Aqueous Solution}

Water molecules have a large dipole moment, even during the crystallization of salts, for instance, when forming complexes of hydrates of $\mathrm{FeCl}_{2} \cdot 4 \mathrm{H}_{2} \mathrm{O}, \mathrm{NiCl}_{2} \cdot 6 \mathrm{H}_{2} \mathrm{O}$, and $\mathrm{CoCl}_{2} \cdot 6 \mathrm{H}_{2} \mathrm{O}$ salts. Molecules of salt dissociate in water, and a weak electrolyte forms [11]. During hydrolysis of the salt, the salt ions bind to hydrogen $\mathrm{H}^{+}$or hydroxyl $\mathrm{OH}^{-}$ions. According to the Le Chatelier principle, a decrease in the concentration of ions should lead to the further decomposition of water molecules into ions. If one of the ions participates in the formation of the electrolyte, then the other ion accumulates in the solution and changes the $\mathrm{pH}$ of the medium. Therefore, to enhance the hydrolysis of salt, the solution must be diluted and heated [11]. According to the law of active masses, when one of the hydrolysis products is introduced into the solution, the hydrolysis of the salt decreases. Upon removal of the hydrolysis product, the hydrolysis of the salt increases.

\section{Hydrolysis of the Iron, Cobalt and Nickel Chlorides}

Here is the equation at the first stage of hydrolysis of iron (II) chloride $\mathrm{FeCl}_{2}$ [11]:

Complete ionic equation: $\mathrm{Fe}^{2+}+2 \mathrm{Cl}^{-}+\mathrm{HOH} \leftrightarrow \mathrm{FeOH}^{+}+$ $2 \mathrm{Cl}^{-}+\mathrm{H}^{+}$.

The hydrolysis of cobalt chloride $\mathrm{CoCl}_{2}$ at the first stage.

Complete ionic equation: $\mathrm{Co}^{2+}+2 \mathrm{Cl}^{-}+\mathrm{HOH} \rightleftarrows \mathrm{CoOH}^{+}+$ $2 \mathrm{Cl}^{-}+\mathrm{H}^{+}$.

The hydrolysis of nickel chloride $\mathrm{NiCl}_{2}$ at the first stage.

Complete ionic equation: $\mathrm{Ni}^{2+}+2 \mathrm{Cl}^{-}+\mathrm{HOH} \rightleftarrows \mathrm{NiOH}^{+}+$ $2 \mathrm{Cl}^{-}+\mathrm{H}^{+}$.

\section{Faraday Law}

The content of the main components in the sediment during electrochemical deposition is associated with the Faraday law through the electrochemical equivalent, where $\mathrm{m}$ is the mass of the deposited metal released per unit area of the electrode, $\mathrm{J}$ is the current density at the cathode, and $\tau$ is the time of the electrochemical deposition process.

The electrochemical equivalent is expressed by the formula:

$$
\mathrm{K}=\mathrm{M} / \mathrm{nF} \text {, }
$$

where $\mathrm{M}$ is the atomic mass of the metal, $\mathrm{n}$ is the metal valency is the ion charge, $\mathrm{F}$ is the Faraday number, and $\mathrm{M} / \mathrm{n}$ is the equivalent mass that is calculated as $26.8 \mathrm{~A} / \mathrm{h}$.

The current density and time are external parameters of the deposition process, and the electrochemical equivalent is a property of the composition and temperature of the electrolyte, cathode material, and current density, all of which determine the current cathode output and the content of components in the precipitate. The composition of the electrolyte determines the formation of metal ions. To increase the cathode yield, complexing additives were introduced into the electrolyte.

$$
\mathrm{K}=100 /\left(\mathrm{P}_{1} / \mathrm{K}_{1}+\mathrm{P}_{2} / \mathrm{K}_{2}+\mathrm{P}_{3} / \mathrm{K}_{3}\right),
$$

The electrochemical equivalent for alloys is determined by the above formula: P1, P2, P3 - the content of the alloy components, $\%$ and $\mathrm{K} 1, \mathrm{~K} 2, \mathrm{~K} 3$ - the electrochemical equivalents of the components. For practical use, it is convenient to use electrochemical equivalents, namely, the volumetric $\mathrm{Kob}=\mathrm{K} / \rho\left[\mathrm{mm}^{3} / \mathrm{A} \cdot \mathrm{h}\right]$ and linear Wedge $=\mathrm{Kob} / \mathrm{S}$ $=\mathrm{K} / \rho \mathrm{S}[\mathrm{mm} / \mathrm{A} \cdot \mathrm{h}]$ per $1 \mathrm{~cm}^{2}$ of surface, where $\rho$ is the metal density and $S$ is the surface area of the deposition [11]. Table 2 shows the electrochemical equivalents for iron, cobalt and nickel, as well as those calculated for the permalloy and three-component $\mathrm{CoNiFe}$ alloy with an equal content of components.

The wedge value is $1.254 \mathrm{~mm} /(\mathrm{Ah})$ for bivalent cobalt $\mathrm{Co}^{2+}, 1.236 \mathrm{~mm} /(\mathrm{Ah})$ for bivalent nickel $\mathrm{Ni}^{2+}, 1.32 \mathrm{~mm} /(\mathrm{Ah})$ for ferrous iron $\mathrm{Fe}^{2+}, 1.251 \mathrm{~mm} /(\mathrm{Ah})$ for permalloy $\mathrm{Ni}_{81} \mathrm{Fe}_{19}$, and $1.264 \mathrm{~mm} /(\mathrm{Ah})$ for the ternary alloy $\mathrm{Co}_{33.3} \mathrm{Ni}_{33.3} \mathrm{Fe}_{33.3}$.

The content of the basic elements in the chloride electrolyte for the electrochemical deposition of $\mathrm{CoNiFe}$ can be changed, and the deposition rate can be controlled but not above the limit determined by the electrochemical equivalent. Electrolyte additives alter the chemical reactions in the electrolyte and the ion charges. Furthermore, the electrochemical equivalent depends on the charge of the metal ion deposited on the cathode.

TABLE 2: ELECTROCHEMICAL EQUIVALENTS

\begin{tabular}{cccccc}
\hline Metal or alloy & Valence & $\begin{array}{c}\mathrm{K}, \\
\mathrm{g} / \mathrm{A} \cdot \mathrm{h}\end{array}$ & $\begin{array}{c}\mathrm{K}_{\mathrm{vol}}, \\
\mathrm{mm} / \mathrm{A} \cdot \mathrm{h}\end{array}$ & $\begin{array}{c}\mathrm{K}_{\text {lin/ }} \mathrm{cm}^{2}, \\
\mathrm{~mm} / \mathrm{A} \cdot \mathrm{h}\end{array}$ & $\begin{array}{c}\rho, \\
\mathrm{kg} / \mathrm{d} \\
\mathrm{m}^{3}\end{array}$ \\
\hline Cobalt & 2 & 1,08 & 125,4 & 1,254 & 8,92 \\
Nickel & 3 & 0,756 & 86,4 & 0,864 & \\
& 2 & 1,092 & 123,6 & 1,236 & 8,84 \\
Iron & 3 & 0,726 & 82,2 & 0,822 & \\
$\mathrm{Ni}^{2+}{ }_{81} \mathrm{Fe}^{2+}{ }_{19}$ & 3 & 1,044 & 132 & 1,32 & 7,87 \\
$\mathrm{Co}^{2+}{ }_{33,3} \mathrm{Ni}^{2+}{ }_{33,3}$ & & 0,69 & 87,6 & 0,876 & \\
$\mathrm{Fe}^{2+}{ }_{33,3}$ & & & & 1,251 & \\
\hline
\end{tabular}

$$
\mathrm{m}=\mathrm{K} \mathrm{J} \tau
$$


E. Ionic Equilibria during Hydrolysis of $\mathrm{FeCl}_{2}, \mathrm{CoCl}_{2}$, $\mathrm{NiCl}_{2}$

In [12], ionic equilibria in the $\mathrm{FeCl}_{2}$ electrolyte were considered according to the results of the thermodynamic calculations of equilibrium constants, as well as equations of mass and charge balance. Then, the resulting charge of ions was compared for compliance with the $\mathrm{pH}$ value. It was shown that an $\mathrm{FeCl}_{2}$ solution with a concentration of up to 4 $\mathrm{mol} / \mathrm{l}$ at room temperature contained a high number of singly charged ions $\left(\mathrm{Fe}^{2+} \mathrm{Cl}^{-}\right)^{+}$, few $\mathrm{Fe}^{2+}$ ions, few neutral molecules, and very few hydroxide ions $\left(\mathrm{Fe}^{2+} \mathrm{OH}^{-}\right)^{+}$.

These data refute the notion commonly accepted in electrochemical deposition of the complete dissociation of salts in an electrolyte. An increase in the concentration of $\mathrm{FeCl}_{2}$ or the addition of hydrochloric acid to the solution increases the content in the electrolyte of singly charged ions $\left(\mathrm{Fe}^{2+} \mathrm{Cl}^{-}\right)^{+}$and neutral molecules of $\mathrm{FeCl}_{2}{ }^{0}$, while decreasing the number of doubly charged $\mathrm{Fe}^{2+}$ ions. At a low salt concentration in the solution, almost identical concentrations of $\mathrm{Fe}^{2+}$ and $\left(\mathrm{Fe}^{2+} \mathrm{Cl}^{-}\right)^{+}$ions are obtained.

It was shown in [13] that in solutions of $\mathrm{CoCl}_{2}$ and $\mathrm{NiCl}_{2}$ with a concentration of $1 \mathrm{~mol} / \mathrm{l}$ at room temperature, the almost complete dissociation of salts occurs. The quantity of singly charged $\mathrm{CoCl}^{+}$and $\mathrm{NiCl}^{+}$ions in a mixed solution was 10 times less than that of doubly charged $\mathrm{Co}^{2+}$ and $\mathrm{Ni}^{2+}$ ions and a thousand times less than that of neutral chloride molecules. In a mixed solution, the concentration of singly charged cobalt $\mathrm{CoCl}^{+}$ions decreased by $30 \%$, and singly charged nickel ions $\mathrm{NiCl}^{+}$increased by $30 \%$. For singly charged ions, a manifestation of the mutual influence of impurities on the ion balance, as well as the presence of hydrochloric acid, was noticeable.

\section{F. Partial Ion Currents}

The value of the potential difference between the cathode and the anode determines the electric field strength in the electrolyte, which determines the speed of ions and the current density in the interelectrode space.

$$
\mathrm{J}=\mathrm{q} \mathrm{n} \mathrm{uE}
$$

where $\mathrm{q}$ is the electron charge, $\mathrm{n}$ is the concentration of ions with different charges, $u$ is the mobility of ions, $E$ is the electric field in the space between the anode and cathode, and $\mathrm{u} E$ is the speed of ions.

The sum of the currents in each section of the region between the cathode and anode is constant due to the condition of current continuity. The deposition of ions at the cathode fixes the composition of the current.

$$
\begin{gathered}
\mathrm{J}=\mathrm{qE}\left[(\mathrm{n} \mathrm{u})\left\langle(\mathrm{FeCl})^{+}\right\rangle+(\mathrm{n} \mathrm{u})\left\langle\mathrm{Fe}^{2+}\right\rangle+(\mathrm{n} \mathrm{u})\left\langle(\mathrm{CoCl})^{+}\right\rangle+(\mathrm{n}\right. \\
\left.\mathrm{u})\left\langle\mathrm{Co}^{2+}\right\rangle+(\mathrm{n} \mathrm{u})\left\langle(\mathrm{NiCl})^{+}\right\rangle+(\mathrm{n} \mathrm{u})\left\langle\mathrm{Ni}^{2+}\right\rangle\right]
\end{gathered}
$$

In an electrolyte containing three components, the difference in the charge of ions and their mobility determines the difference in the partial current density for each of the components in the form of singly charged and doubly charged ions.

As a result of the difference in the partial currents of the components, differences arise in the mass transfer, discharge of ions at the cathode, and formation of a precipitate.
The chemical composition of an electrolytic alloy formed on a cathode during the joint discharge of ions of two metals can be determined [14] by the ratio of the partial recovery currents of the individual components according to the following equation:

$$
(\mathrm{Me} 1 / \mathrm{Me} 2)_{\text {alloy }}=\mathrm{i} 1 / \mathrm{i} 2 \cdot \mathrm{z} 2 / \mathrm{z} 1 \text {, }
$$

where $\mathrm{Me}, \mathrm{i}$, and $\mathrm{z}$ are the metal concentration in the alloy (atomic fraction or percent), partial current and metal valence, respectively.

With changing electrolysis conditions, the ratio of currents i1/i2 does not remain constant, which determines the dependence of the alloy composition on various parameters. The nature of the influence of individual factors depends on the kinetic region in which the joint discharge occurs in the electrochemical kinetics region or in the diffusion region.

Using the dependences of the partial currents on the potential, equations are obtained that determine the dependence of the alloy composition on the potential and the required ratio of the concentrations of each component in the solution.

\section{G. Electrode Polarization Potential}

The deviation of the electrode potential from the stationary (equilibrium) value observed during current transmission is called the polarization (overvoltage) of the electrode.

In [15], the mechanism of electrodeposition of nickel, iron, and their mixture with a sulfide electrolyte was studied. As shown in Fig. 15, the nickel reduction potential of -0.75 $\mathrm{V}$ was more positive than iron $-0.92 \mathrm{~V}$ and the mixed solution of $-0.88 \mathrm{~V}$, i.e., this result had an indeterminate meaning. However, in a joint discharge, the reduction rate of nickel ions was much lower than that of iron. The potential for cobalt reduction was $-0.42 \mathrm{~V}$, which was the most positive; therefore, the deposition of cobalt was least limited by the formation of a double charged layer on the cathode.

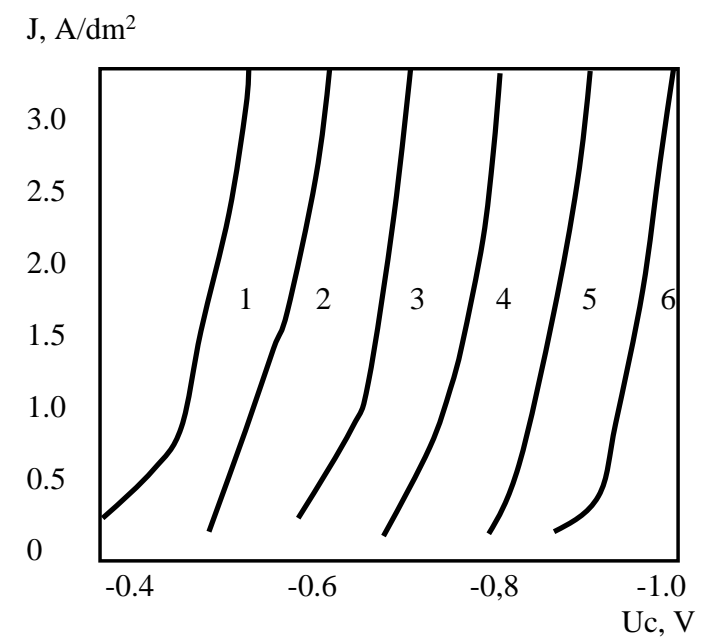

Fig. 15. Polarization curves during the electrodeposition of cobalt, nickel and iron from the following solutions at $\mathrm{pH}=1.9$ and with the addition of $30 \mathrm{~g} / \mathrm{l}$ boric acid: $1 . \mathrm{CoSO}_{4}, 4 . \mathrm{NiSO}_{4}, 6 . \mathrm{FeSO}_{4}, 5$. mixed $\mathrm{NiSO}_{4}$ and $\mathrm{FeSO}_{4}$ at $25{ }^{\circ} \mathrm{C} ; 2 . \mathrm{NiSO}_{4}$, and $3 . \mathrm{FeSO}_{4}$ at a temperature of $95{ }^{\circ} \mathrm{C}$ [15] 
The rate of the joint reduction of nickel and iron ions has an average value between their separate values, but the result does not add up. At temperatures above $90{ }^{\circ} \mathrm{C}$, the reduction rate of nickel ions is higher than that of iron ions. In this case, the polarization curves show a nickel reduction potential that is $-0.59 \mathrm{~V}$ more positive than iron $-0.7 \mathrm{~V}$. The reduction potential does not cause the abnormal deposition at high temperature to change to the normally predominant nickel deposition.

\section{H. Consequence}

The analysis of the factors determining the change in the composition of films with a change in the current density shows that there is an obvious connection with the change in the mass transfer of ions in the electrolyte. A low nickel concentration is determined by its main contribution of nickel to the partial current of ions with a double charge and the low mobility of $\mathrm{Ni}^{2+}$ ions. High concentrations of cobalt and iron are associated with the high mobility of singly charged ions $\left(\mathrm{Co}^{2+} \mathrm{Cl}^{-}\right)^{+},\left(\mathrm{Fe}^{2+} \mathrm{Cl}^{-}\right)^{+}$and an increase in their speed with an increasing electric field in the interelectrode space.

In addition to the type of ions, the mass transfer depends on the viscosity of the solution, which increases with increasing concentrations of the components and decreases with increasing temperature [16]. The electrolyte can be stirred mechanically by means of a magnetically driven stirrer, by the rotation or reciprocating motion of the cathode, and by ultrasonic action, thereby leading to a change in the mass transfer of ions and a decrease in the threshold voltage at which current growth begins. In [17], potential-current density curves were presented, and these curves showed that mixing the electrolyte increased the limiting current and concentration polarization.

\section{CONCLUSION}

The choice of a chloride electrolyte with a ratio of $\mathrm{C}_{\mathrm{Ni}} / \mathrm{C}_{\mathrm{Ni}} / \mathrm{C}_{\mathrm{Co}}=1 / 1 / 1$, the development of technology for the preparation of an electrolyte and the deposition process at a temperature of $70{ }^{\circ} \mathrm{C}$ allowed us to confirm the mechanism behind the abnormal deposition of $\mathrm{Co}, \mathrm{Fe}, \mathrm{Ni}$. The results pointed to the difference in the ionization of iron, cobalt and nickel. Films were obtained without mechanical stresses, and these films contained a uniform structure and high magnetic parameters without the need for a high annealing temperature. The chosen method of deposition with a chloride electrolyte, while taking into account the ion charge, allowed us to obtain reproducible electrochemical deposition of $\mathrm{CoNiFe}$ films with a small coercive force.

Electrochemical deposition was carried out at the temperature of $70^{\circ} \mathrm{C}$ from chloride electrolyte with component ratio $\mathrm{C}_{\mathrm{Ni}} / \mathrm{C}_{\mathrm{Fe}} / \mathrm{C}_{\mathrm{Co}}=1 / 1 / 1$. A review of the literature [1]-[5], [18]-[50] shows that none of the researchers used this method of research.

\section{REFERENCES}

[1] Ye. Sverdlov, Yu. Rosenberg, Yu.I. Rosenberg, R. Zmood, R. Erlich, S. Natan, Yo. Shacham-Diamand, "The electrodeposition of cobaltnickel-iron high aspect ratio thick film structures for magnetic MEMS applications," Microelectronic Engineering 2004, 76:258265.

[2] K. Ohashi, Y. Yasue, M. Saito, K. Yamada, T. Osaka, M. Takai, and $\mathrm{K}$ Hayashi, "Newly developed inductive write head with electroplated CoNiFe thin film," IEE Transactions on Magnetics 1998, 34(4), 1432.

[3] X. Liu, P. Evans, and G. Zangari, "Electrodeposition Co-Fe and CoFe-Ni Alloy Films For Magnetic Recording Write Heads" IEEE Transactions of Magnetics 2000, 36(5): 5410 -5415.

[4] I. Hanafi, A.R. Daud, Sh. Radiman, "Potentiostatic electrodeposition of Co-Ni-Fe thin films from sulfate medium," Journal of Chemical Technology and Metallurgy 2016, 51(5):547-555.

[5] Y. Yang, "Preparation of Fe-Co-Ni ternary alloys with electrodeposition," Int. J. Electrochem. Sci. 2015, 10: 5164 - 5175.

[6] Robert Tikhonov, "Congruent electrochemical deposition of $\mathrm{NiFe}$ alloy" Lambert Academic Publishing, 2019, P. 193.

[7] R.D. Tikhonov, "Elektroosajdenie splava NiFe dly proizvodstva integralnyh microshem," Galvanotehnica 2015, 4: 13-19.

[8] R.D. Tikhonov, A.A. Cheremisinov, D.V. Gorelov, and Ju.V. Kasakov, "Plenochnye koncentratory magnitnogo poly na osnove splava CoNiFe" Nano- I microsistemnay tehnika 2020, 22(3): 123135.

[9] R.D. Tikhonov, "Magnetic properties of permalloy films deposited electrochemically by the Tikhonov method," British Open Journal of Chemical Sciences 2018, 2(2): 1-10, Available online at http://borpub.com/Journals.php.

[10] R.D. Tikhonov and A.A. Cheremisinov, "Magnetization of Permalloy Films" Russian Microelectronics 2017, 46(2): 95-104.

[11] N.V. Korovin, "Obtschay himiy" Moscow 1998, P. 559.

[12] Man-Seung Lee, "Use of the Bromley Equation for the Analysis of Ionic Equilibria in Mixed Ferric and Ferrous Chloride Solutions at $25^{\circ} \mathrm{C}$ " Metallurgical and materials transections B 2006, 37(2): 173.

[13] Man-Seung Lee and Young-Joo Oh, "Chemical Equilibria in a Mixed Solution of Nickel and Cobalt Chloride" The Japan Institute of Metals, Materials Transactions 2005, 46(1): 59 - 63.

[14] B.P. Iuriev, "O zavisimosty sostava electroliticheskogo splava ot uslovii electroliza" Journal prikladnoy himii 1974, 47(10):22322236

[15] A.T. Vagramayn, T.A. Fatueva, "O sovmestnom razrayde ionov metallov v realnyh soprayjennih sistemah” Doklady AN SSSR 1960, 135(6):1413-1416.

[16] V.N. Tseluikin and N.D. Solov'eva, "Viscous Flow of Concentrated Aqueous Solutions of $\mathrm{NiCl}_{2}+\mathrm{FeCl}_{2}$ " Rus. journal of appl. Chem. 2005, 78(11):1824-1826.

[17] Iu.A. Bagdasarova, N.S. Bagdasarov, "Phiziko-hemicheskie osnovy korrozii," Uchebnoe posobie 2004, Samara.

[18] A. Nakamura, M. Takai, K. Hayashi, T. Osaka, "Preparation and Magnetic Properties of CoNiFe Thin Film by Electrodeposition," Materials Science 1996

[19] T. Osaka, T. Sawaguchi, F. Mizutani, T. Yokoshima, M. Takai, and Y. Okinaka, "Effects of saccharin and thiourea on sulfur inclusion and coercivity of electroplated soft magnetic CoNiFe film," Journal of The Electrochemical Society 1999, 146( ): 3295-3299.

[20] N. Zech, E.J. Podlaha, and D. Landolt, "Anomalous Codeposition of Iron Group Metals I. Experimental Results," Journal of The Electrochemical Society 1999, 146 (8): 2886-2891.

[21] I Tabakovic, S Riemer, V Inturi, P Jallen, A Thayer, "Organic additives in the electrochemical preparation of soft magnetic CoNiFe films," Journal of The Electrochemical Society 2000, 147 (1), 219 226.

[22] I. Tobakovic, V. Inturi, and S. Riemer, "Composition, structure, stress, and coercivity of electrodeposited soft magnetic CoNiFe films," Journal of The Electrochemical Society 2002, 149(1): I8-22.

[23] L. Perez, K. Attenborough, J. De Boeck, J.P. Celis, C. Aroca, P. Sánchez, E. López, M.C. Sánchez, "Magnetic properties of CoNiFe alloys electrodeposited under potential and current control conditions," J. Magn. Magn. Mater. 2002, 242-245(1): 163-165.

[24] D. Kim, D.Y. Park, B.Y. Yoo, P.T.A .Sumodjo, N.V. Myung, "Magnetic properties of nanocrystalline iron group thin film alloys electrodeposited from sulfate and chloride baths" Electrochimica Acta 2003, 48: 819-830.

[25] Q. Huang and E.J. Podlaha, "Simulation of Pulsed Electrodeposition for Giant Magnetoresistance $\mathrm{FeCoNiCu} / \mathrm{Cu}$ Multilayers" Journal Electrochemical Society 2004, 151(2):119-126. 
[26] H. Nakano, M. Matsuno, S. Oue, M. Yano, Sh. Kobayashi, and H Fukushima, "Mechanism of Anomalous Type Electrodeposition of Fe-Ni Alloys from Sulfate Solutions" The Japan Institute of Metals, Materials Transactions 2004, 45(11): 3130-3135.

[27] D.Y. Park, B.Y. Yoo, S. Kelcher, N.V. Myung, "Electrodeposition of low-stress high magnetic moment Fe-rich FeCoNi thin films,' Electrochimica acta 2006, 51: 2523-2530.

[28] Tiffany Yun, Wen Jiang, "Effects of additives on magnetic properties of electroplated CoNiFe films," Master's Theses, San Jose State University, 2008.

[29] J.F. Rohan, B.M. Ahern, K. Reynolds, S. Crowley, D.A. Healy, F.M.F. Rhen, S. Roy, "Electroless thin film CoNiFe-B alloys for integrated magnetics on Si," Electrochimica Acta 2009, 54(6):1851.

[30] L. P'eter, A. Csik, K. Vad, E. Toth-Kadar, A. Pekker, and G. Molnár, "On the composition depth profile of electrodeposited Fe-Co-Ni alloys," Chemistry, Electrochimica Acta 2010, 55(16): 4734-4741.

[31] K. Sundaram, V. Dhanasekaran, T. Mahalingam, "Structural and magnetic properties of high magnetic moment electroplated $\mathrm{CoNiFe}$ thin films," Ionics 2011, 17(9):835-842.

[32] L.X. Phua, N.N. Phuoc, C.K. Ong, "Effect of Ni concentration on microstructure, magnetic and microwave properties of electrodeposited NiCoFe films," Journal of Alloys and Compounds 2012, 543:1-6.

[33] J Gong, S Riemer, A Morrone, V Venkatasamy, M Kautzky, I Tabakovic, "Composition gradients and magnetic properties of 5$100 \mathrm{~nm}$ thin CoNiFe films obtained by electrodeposition," Journal of the Electrochemical Society 2012, 159 (7), D447-D454.

[34] Li Jian-mei and all, "Effect of boron/ phosphorus containing additives on electrodeposited CoNiFe soft magnetic thin films," Transactions of Nonferrous Metals Society of China 2013, 23(3):674.

[35] A. Azizi, A. Yourdkhani, D. Cutting, N. Pesika, "Tuning the Crystal Structure and Magnetic Properties of CoNiFeB Thin Films,' Chemistry of Materials 2013, 25(12):2510-2514.

[36] N.G. Valko, W.G. Gurtovoy, "Structure and properties of coatings $\mathrm{Co}-\mathrm{Ni}-\mathrm{Fe}$, electrolytically besieged by X-ray radiation," Fisika tverdogo tela 2013, 55(11): 2086-2089.

[37] Z.N. Kayani, S. Riaz, Sh. Naseem, "Structural and magnetic properties of FeCoNi thin films," Indian J. Physics 2014, 88(2): 17 23.

[38] C.H. Kuru, H. Kockar, O. Demirbas, M. Alper, "Characterizations of electrodeposited $\mathrm{NiCoFe}$ ternary alloys: Influence of deposition potential," Journal of Materials Science Materials 2015, 26(6): 4046.

[39] Yo. Watanabe, M. Otsubo, A. Takahashi, H. Fukunaga "Temperature Characteristics of a Fluxgate Current Sensor with FeNi-Co Ring Core</b," IEEE Transactions on Magnetics 2015 51(11):1-1.

[40] N.I. Kourov, V.G. Pushin, A.V. Korolev, Yu.V. Knyazev, M.V. Ivchenko, Yu.M.Ustyugov," Peculiar features of physical properties of the rapid quenched $\mathrm{AlCrFeCoNiCu}$ high-entropy alloy," Journa of Alloys and Compounds 2015, 636: 304-309.

[41] S. Romankov, Y.C. Park, and I.V. Shchetinin, "Mechanical intermixing of elements and self-organization of (FeNi) and $(\mathrm{CoFeNi})$ nanostructured composite layers on a $\mathrm{Ti}$ sheet under ball collisions," Journal of Alloys and Compounds 2015, 653: 175-186.

[42] T. Yanai, and all, "Electroplated Fe-Co-Ni films prepared from deep eutectic-solvent-based plating baths," AIP Advances 2016, 6 055917.

[43] K. Eguchi, K. Azuma, T. Akiyoshi, H. Fukunaga, "DC/Pulse Plating of Fe-Ni-Co Films," Conference: 2016 International Conference of Asian Union of Magnetics Societies (ICAUMS)

[44] T. Yanai, K. Koda, K. Eguchi, K. Takashima, "Effect of Ammonium Chloride in Plating Baths on Soft Magnetic Properties of Electroplated Fe-Ni Films," IEEE Transactions on Magnetics 2017, PP(99):1-1.

[45] D. Li, and E. Podlaha, "Template-Assisted Electrodeposition of FeNi-Co Nanowires: Effects of Electrolyte $\mathrm{pH}$ and Sodium Lauryl Sulfate," Journal of The Electrochemical Society 2017, 164 (13) D843.

[46] T. Yanai,and all, "Electroplated $\mathrm{Fe}-\mathrm{Co}-\mathrm{Ni}$ films prepared in ammonium-chloride-based plating baths," AIP ADVANCES 2018 8(056127): 1-5

[47] S. Romankov, Y.C. Park, and I.V. Shchetinin, "Structural transformations in $(\mathrm{CoFeNi}) / \mathrm{Ti}$ nanocomposite systems during prolonged heating," Journal of Alloys and Compounds 2018, 745: 44.

[48] I Tabakovic, V Venkatasamy, "Preparation of metastable CoFeNi alloys with ultra-high magnetic saturation $(\mathrm{Bs}=2.4-2.59 \mathrm{~T})$ by reverse pulse electrodeposition," Journal of Magnetism and Magnetic Materials 2018, 452: 306-314.
[49] D. Li, "Fabrication of Fe-Ni-Co Nanowires by Electrodeposition Coupled with Hydrogen Evolution Reaction and Electrochemical Detection of Pyocyanin," A Thesis of Doctor Northeastern University, Boston, Massachusetts 2018.

[50] H. Cesiulis, N. Tsyntsaru, E.J. Podlaha, D. Li and J. Sort, "Electrodeposition of Iron-Group Alloys into Nanostructured Oxide Membranes: Synthetic Challenges and Properties," Current Nanoscience 2018, 14(1): 1-16.

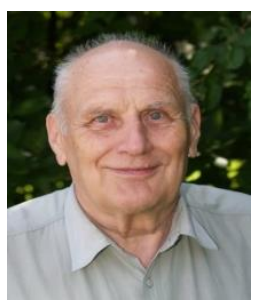

Robert Dmitrievich Tikhonov was born in 1937 in Moscow.

$\mathrm{He}$ has been working in microelectronics since 1959, after graduating from the Moscow Power Engineering Institute. He originally developed the technology for growing monocrystals of silicongermanium and found a way to obtain defect-free crystals with a $\mathrm{Si}$ content to $5.5 \%$ due to the dynamics of displacement.

From 1960 to 1963 , he created the first solid (integrated) amplifier circuits, i.e., he was among the pioneers of integrated electronics. From 1963 to 1970, he studied in graduate school and performed work on manufacturing and measuring a vacuum thin-film transistor based on CdS in a single cycle. Since 1970 to 1974, he participated in the development of integrated TTL-type circuit technology. From 1974 to 1986, he oversaw as Chief Designer works on the creation of two series of CMOS LIC 5747 and 51522 for aerospace computing machines on the "MIR" station. Successful work on spacecraft computers confirmed the high quality of the work done. From 1986 to 2002, he developed a design and manufacturing technology for a power MOS transistor with a pinch resistor and became a Ph.D. candidate of technical sciences at the Moscow Institute of Electronic Technology. From 1966 to 1970, he taught physics at the Moscow Institute of Electronic Technology. From 2002 to 2013, he developed technology and simulations of new magnetotransistor designs. Also, he published magnetotransistor articles and a book "Triple collector magnetotransistor". Over the past seven years, he has been developing magnetic field concentrators based on permalloy films.

Mr. Tikhonov has published 4 books, 134 articles, received 32 patents, and shared 80 reports in conferences.

1. Some Features of Dual Collector Lateral Bipolar Magnetotransistor//Book "Solid State Electronics Research Advances" Nova Science Publishers 2009.

2. Трехколлекторный магнитотранзистор//Lambert Academic Publishing 2013.

3. The volume concentration-recombination mechanism responsible for negative current sensitivity//Quarterly Physics Review 3(2), July 2017 Copyright KEI Journals.

4. Congruent electrochemical deposition of $\mathrm{NiFe}$ alloy//Lambert Academic Publishing 2019. 